\title{
Pegfilgrastim compared with Filgrastim after autologous hematopoietic peripheral blood stem cell transplantation
}

\author{
Gaëtan Vanstraelen*, Pascale Frère*, \\ Marie-Christine Ngirabacu, Evelyne Willems, Georges Fillet, and Yves Beguin \\ Department of Medicine, Division of Hematology, University of Liege, Liege, Belgium
}

(Received 30 July 2005; revised 10 November 2005; accepted 21 November 2005)

\begin{abstract}
In order to assess the effect of Pegfilgrastim on the duration of neutropenia and clinical outcome of patients after autologous peripheral blood stem cell (PBSC) transplantation, we compared 20 consecutive patients with lymphoma or multiple myeloma receiving a single 6-mg dose of Pegfilgrastim on day 1 posttransplant to an historical control group of 60 patients receiving daily Filgrastim $5 \mu \mathrm{g} / \mathrm{kg}$ starting on day 1 posttransplant. The duration of neutropenia was similar in the Pegfilgrastim group compared with the control group. There were no differences in time to neutrophil, erythroid, or platelet engraftment nor in the incidence of fever and infections. The duration of antibiotic therapy, transfusion support, and time to hospital discharge were similar in the two groups. However, after initial hematopoietic reconstitution, we observed significantly higher values of lymphocytes (e.g., $1660 \pm 1000$ versus $970 \pm 460$ on day $80, p=0.0002$ ), neutrophils (e.g., $3880 \pm 2030$ versus $2420 \pm 1500$ on day $25, p=0.0004$ ), reticulocytes (e.g., $148,160 \pm 90,590$ versus $87,140 \pm 65,920$ on day $25, p<0.0001)$, and platelets (e.g., 210,700 $\pm 116,090$ versus $150,240 \pm 58,230$ on day $55, p=0.0052)$ up to day 100 in the Pegfilgrastim group compared with the Filgrastim group. These observations had no impact on clinical outcome of the patients after day 30 due to the low incidence of infectious events after engraftment in autologous PBSC transplantation. We conclude that the effect of Pegfilgrastim administrated on day 1 posttransplant is comparable to that of daily Filgrastim on initial hematopoietic reconstitution. The possibly superior effect of Pegfilgrastim on cell counts we observed after initial engraftment should be further tested in a prospective randomized trial. (c) 2006 International Society for Experimental Hematology. Published by Elsevier Inc.
\end{abstract}

High-dose chemotherapy followed by autologous hematopoietic stem cell transplantation (HCT) is a widely accepted treatment modality for several selected hematologic malignancies. Low neutrophil counts in the early posttransplant period facilitate the occurrence of severe infectious complications and have a significant impact on overall morbidity and mortality after autologous HCT [1-4]. Various reports have shown that recombinant hematopoietic growth factors such as granulocyte colony-stimulating factor (G-CSF) [5-12] or granulocyte-macrophate colony-stimulating factor (GM-CSF) [13] significantly reduce the time to neutrophil recovery following autologous peripheral blood stem cell (PBSC) transplantation. Moreover, these previous studies have shown that the use of these myeloid growth

\footnotetext{
Offprint requests to: Yves Beguin, M.D., University of Liege, Department of Hematology, CHU Sart Tilman, 4000 Liege, Belgium; E-mail: yves.beguin@chu.ulg.ac.be

*These authors contributed equally to this work.
}

factors significantly decreases number of bacterial infections, number of days on antibiotics, and duration of initial hospitalization.

Research investigations have shown that their modification by chemical addition of poly(ethylene glycol) can alter the pharmacokinetic and pharmacodynamic properties of various proteins to significantly increase the time the modified proteins remain effective in the circulation [14]. Molineux et al. have developed a form of Filgrastim modified by the addition of a linear pegylated (PEG) molecule of $20 \mathrm{kD}$ covalently bound to the $\mathrm{N}$-terminus showing a sustained duration of action in vivo [15]. Clinical studies have demonstrated that Pegfilgrastim was as safe and effective as daily Filgrastim in several settings [16-20]. Pegfilgrastim administered once per cycle after chemotherapy for nonsmall cell lung cancer (NSCLC) [21], breast cancer $[16,17]$, or lymphoma $[18,20]$ provided neutrophil support and presented a safety profile comparable to that of daily Filgrastim. Successful transplantation of PBSC mobilized 
by chemotherapy and a single dose of Pegfilgrastim has been reported in patients with multiple myeloma [19]. The ability of a single injection of Pegfilgrastim to improve neutrophil recovery following bone marrow transplantation has been illustrated in rhesus macaques [22]. Recently, a few articles [23,24] and abstracts [25,26] compared the administration of a single 6-mg dose of Pegfilgrastim with daily Filgrastim after autologous PBSC transplantation. However, in these studies, the two treatments were started on differing days posttransplant (i.e., day +3 versus day +5 [26], day +2 versus day +5 [25], day +1 versus days +1 or +4 [23], and day +5 versus day +7 [24]). In addition, the evolution of hematologic parameters after initial hematopoietic recovery is not known. We present here our experience with the use of Pegfilgrastim compared with Filgrastim, both started on day 1 posttransplant, with 100day follow-up after autologous PBSC transplantation.

\section{Patients and methods}

\section{Patients}

Between May 2004 and November 2004, 20 consecutive autologous stem cell transplantation recipients with lymphoid malignancies were treated with Pegfilgrastim after transplantation. They were compared to a historical control group of 60 patients selected in our database of patients receiving an autologous PBSC transplant and daily Filgrastim starting on day 1 in the preceding 3 years. This control group was matched 3:1 with the study group on the basis of age, sex, diagnosis, disease status at time of transplant, transplantation number, and starting day of posttransplant G-CSF. Patient characteristics are given in Table 1. All patients gave written informed consent to analysis of their clinical data and this process was approved by the Ethics Committee of the University of Liège.

\section{PBSC collection and transplantation}

Multiple myeloma patients were mobilized with cyclophosphamide $4.5 \mathrm{~g} / \mathrm{m}^{2}$ and G-CSF $5 \mu \mathrm{g} / \mathrm{kg} / \mathrm{d}$, and lymphoma patients with cyclophosphamide $4.5 \mathrm{~g} / \mathrm{m}^{2}$, VP16 $1.5 \mathrm{~g} / \mathrm{m}^{2}$, and G-CSF. PBSC were harvested in all patients by leukapheresis as previously described $[27,28]$ and stored without further manipulation in liquid nitrogen in $7.5 \%$ dimethylsulfoxide. Conditioning regimens consisted of cyclophosphamide $(120 \mathrm{mg} / \mathrm{kg})+$ total body irradiation (12 Gy) for low-grade lymphoma ( $\mathrm{n}=15)$, BCNU, Etoposide, Ara-C, Melphalan (BEAM) for high-grade lymphoma or Hodgkin's disease $(\mathrm{n}=15)$, and Melphalan $\left(200 \mathrm{mg} / \mathrm{m}^{2}\right)$ for multiple myeloma $(n=50)$. On the day of transplantation, cells were rapidly thawed and infused through a central catheter.

\section{Growth factors}

In the study group, Pegfilgrastim (Neulasta, Amgen, Thousand Oaks, CA, USA) was administered at a single intravenous dose of $6 \mathrm{mg}$ on day 1 posttransplant. In the historical control group, Filgrastim (Neupogen, Amgen, Thousand Oaks, CA, USA) was administered at a dose of $5 \mu \mathrm{g} / \mathrm{kg} / \mathrm{d}$ from day 1 posttransplant until the absolute neutrophil count (ANC) was $\geq 1 \times 10^{9} / \mathrm{L}$ for 3 days or $\geq 10 \times 10^{9} / \mathrm{L}$ for 1 day, whichever came first. In both groups,
Table 1. Patient characteristics

\begin{tabular}{lccc}
\hline & Filgrastim & Pegfilgrastim & $p$ value \\
\hline Number of patients & 60 & 20 & \\
Age (Mean \pm SD) & $56 \pm 9$ & $54 \pm 10$ & \\
Sex & & & \\
$\quad$ Males & $41(68 \%)$ & $13(65 \%)$ & 0.7820 \\
$\quad$ Females & $19(32 \%)$ & $7(35 \%)$ & \\
Disease & $20(30 \%)$ & $10(50 \%)$ & 0.1824 \\
$\quad$ NHL + HD & $40(70 \%)$ & $10(50 \%)$ & \\
$\quad$ MM & $17(28 \%)$ & $9(45 \%)$ & 0.1680 \\
Disease status & $43(72 \%)$ & $11(55 \%)$ & \\
$\quad$ CR & $19(32 \%)$ & $6(30 \%)$ & 0.8890 \\
$\quad$ Not in CR & $41(68 \%)$ & $14(70 \%)$ & \\
Prior autologous HCT & & & \\
$\quad$ Yes & $27(45 \%)$ & $16(80 \%)$ & 0.0065 \\
$\quad$ No & $33(55 \%)$ & $4(20 \%)$ & \\
CMV status & & & \\
$\quad$ CMV+ & & & \\
CMV- & $10.03 \pm 6.25$ & $7.16 \pm 3.82$ & 0.0575 \\
Graft composition $(\mathrm{Mean} \pm \mathrm{SD})$ & CD34 cells $\left(\times 10^{6} / \mathrm{kg}\right)$ & $232.12 \pm 27.11$ & 0.7968 \\
$\quad$ CFU-GM $\left(\times 10^{4} / \mathrm{kg}\right)$ & $281.21 \pm 258.70$ & 232.120
\end{tabular}

NHL, Non-Hodgkin's lymphoma; HD, Hodgkin's disease; MM, multiple myeloma; $\mathrm{CR}$, complete remission.

additional doses of Filgrastim were given when the ANC fell below $1 \times 10^{9} / \mathrm{L}$ at any time before day 100 posttransplant.

\section{Clinical management}

Until engraftment, patients were kept in laminar air flow rooms and received chlorhexidine mouthwashes. Patients also received acyclovir $\left(250 \mathrm{mg} / \mathrm{m}^{2}\right.$ b.i.d. intravenously and then orally as soon as feasible until day 40), oral antifungal prophylaxis with either $400 \mathrm{mg}$ itraconazole or $400 \mathrm{mg}$ fluconazole until day 40, and aerosolized pentamidine until day 120 . All patients were managed with a totally implanted Port-A-Cath catheter (Braun, Melsungen, Germany) that remained in place at least until 1 year posttransplant. In case of fever above $38.3^{\circ} \mathrm{C}$ once or above $38^{\circ} \mathrm{C}$ on three consecutive measurements, empirical antibiotic therapy was started with a combination of cefepim + amikacin [29]. Patients were weekly screened for cytomegalovirus (CMV) by polymerase chain reaction (PCR). Preemptive therapy with ganciclovir (10 $\mathrm{mg} / \mathrm{kg}$ intravenously thrice weekly) was initiated after a positive PCR and discontinued after two consecutive negative results. We used the definitions of the Infectious Diseases Working Party of the European Bone Marrow Transplant Group (EBMT) for diagnosis of bacteremia, fungemia, varicella-zoster virus infections, CMV infection, or disease [30]. Fever of unknown origin was defined as fever alone without clinical sign or bacteriologic documentation.

Complete blood counts were determined in an Advia cell counter (Bayer, Tarrytown, NJ, USA). Red blood cell (RBC) and platelet transfusions were given when the hemoglobin or platelet count were below $8 \mathrm{~g} / \mathrm{dL}$ or $15 \times 10^{9} / \mathrm{L}$, respectively.

\section{Statistical analyses}

Unpaired and paired Student's $t$-tests as well as two-way analysis of variance were used to compare biologic parameters in the two groups. Welsh's correction was used in case of unequal variance. 
Number of transfusions in the two groups was compared using Mann-Whitney $U$-tests. Times to hematopoietic recovery were studied by life table analyses and Wilcoxon rank tests were used for comparisons between groups. Clinical outcome parameters were analyzed by Chi-square tests. Statistical analyses were carried out with Graphpad Prism (Graphpad Software, San Diego, CA, USA).

\section{Results}

\section{Hematopoietic recovery}

There was no significant difference in initial neutrophil engraftment between the two groups. Time to reach an ANC of 0.5 (Fig. 1 ) or $1 \times 10^{9} / \mathrm{L}$ or the number of days with neutropenia (Table 2) were similar in the two groups. Similarly, no difference was seen between the two groups for time to unsupported platelet count $\geq 20$ or $100 \times 10^{9} / \mathrm{L}$ or the number of platelet transfusions (Table 2). There was also no significant difference in time to $1 \%$ reticulocytes or the number of red cell units transfused (Table 2).

After initial hematopoietic recovery, several differences between the groups became apparent. When significant, these differences always consisted in the Pegfilgrastim group showing higher counts compared with the Filgrastim group. The neutrophil count (day 25: $3880 \pm 2030$ versus $2420 \pm 1500 ; p=0.0004)$ remained significantly higher in the study group between days 14 and 30 (Fig. 2), as did the lymphocyte count (day 80: $1660 \pm 1000$ versus $970 \pm 460 ; p=0.0002$ ) between days 56 and 90 (Fig. 2), the monocyte count between days 21 and 24, reticulocytes (day 24: 148,160 \pm 90,590 versus 87,140 \pm 65,920; $p<0.0001$ ) between days 17 and 42 (Fig. 2), and the platelet count (day 56: 210,700 \pm 116,090 versus $150,240 \pm 58,230 ; p=0.0052$ ) between days 35 and day 90 (Fig. 2), respectively.

After the initial hematopoietic recovery and up to day 100, a total of three supplementary doses of Filgrastim

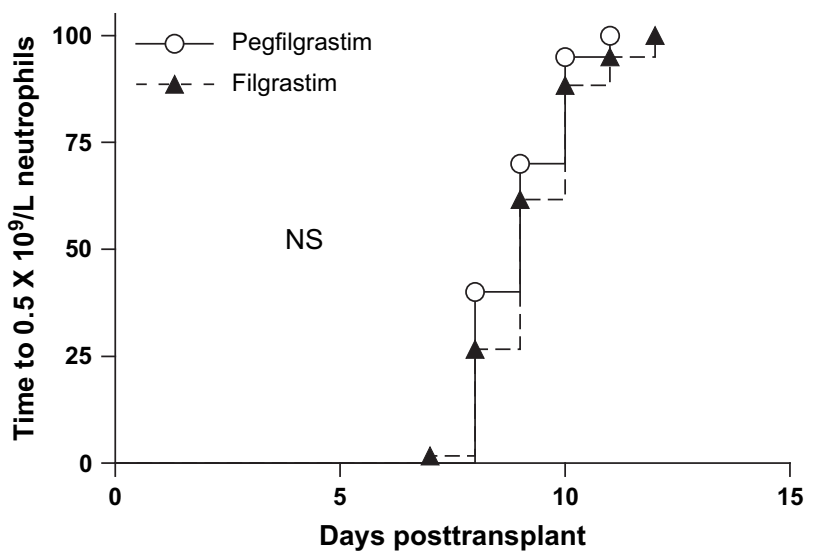

Figure 1. Kaplan-Meier plot of time to $0.5 \times 10^{9} / \mathrm{L}$ neutrophils in the Pegfilgrastim group compared with the Filgrastim group.
Table 2. Hematological recovery after transplantation

\begin{tabular}{|c|c|c|c|}
\hline & Filgrastim & Pegfilgrastim & $p$ value \\
\hline $\begin{array}{l}\text { Days to } 0.5 \times 10^{9} / \mathrm{L} \text { neutrophils } \\
\text { (median) }\end{array}$ & 9 & 8 & 0.2281 \\
\hline $\begin{array}{l}\text { Days to } 1.0 \times 10^{9} / \mathrm{L} \text { neutrophils } \\
\text { (median) }\end{array}$ & 9 & 9 & 0.1620 \\
\hline $\begin{array}{l}\text { Days to } 1 \% \text { reticulocytes } \\
\text { (median) }\end{array}$ & 15 & 13 & 0.1416 \\
\hline $\begin{array}{l}\text { Days to last RBC transfusion } \\
\text { (median) }\end{array}$ & 8 & 7 & 0.6285 \\
\hline $\begin{array}{l}\text { Days to } 20 \times 10^{9} / \mathrm{L} \text { platelets } \\
\quad(\text { median })\end{array}$ & 9 & 9 & 0.6510 \\
\hline $\begin{array}{l}\text { Days to } 100 \times 10^{9} / \mathrm{L} \text { platelets } \\
\quad \text { (median) }\end{array}$ & 31 & 20 & 0.4206 \\
\hline $\begin{array}{l}\text { Days to last platelet transfusion } \\
\text { (median) }\end{array}$ & 7 & 6 & 0.5428 \\
\hline Number of G-CSF injections* & $10.7 \pm 1.7$ & 1 & \\
\hline $\begin{array}{l}\text { Number of additional G-CSF } \\
\text { injections }^{\dagger}\end{array}$ & $0.4 \pm 0.9$ & $0.2 \pm 0.4$ & 0.2513 \\
\hline $\begin{array}{l}\text { Number of red blood cell } \\
\text { transfusions }\end{array}$ & $0.9 \pm 1.6$ & $1.1 \pm 1.6$ & 0.5542 \\
\hline Number of platelet transfusions & $1.0 \pm 1.7$ & $1.2 \pm 1.8$ & 0.7142 \\
\hline
\end{tabular}

*Number of injections until full neutrophil engraftment (see Methods).

${ }^{\dagger}$ Number of injections for secondary neutropenia after initial neutrophil engraftment.

had to be administered to three patients in the Pegfilgrastim group $(0.15 \pm 0.37$ per patient $)$ and a total number of 24 doses to 20 patients in the control group $(0.40 \pm 0.94$ per patient; not significant).

\section{Infections}

Clinically relevant infections occurring within 100 days posttransplant in the two groups are summarized in Table 3. There was no difference between the two groups for the overall incidence of infection, nor for specific rates of bacteremia, other bacterial infections, fungal infections, or zoster infections. The number of patients with CMV infection was higher in the study group, but this was only due to the larger proportion of CMV seropositive patients in this group compared to the control group $(p=0.0065)$. Finally, there was no difference for the number of days with fever, days on antibiotics, days on amphotericin B, or duration of hospitalization. The cost of G-CSF until engraftment was $1237 \pm 277 €$ /patient with Filgrastim versus $1207 € /$ patient with Pegfilgrastim ( $p=0.6210)$.

\section{Discussion}

High-dose chemotherapy followed by autologous HCT is widely used in the treatment of patients with multiple myeloma and lymphoma. Severe and life-threatening infections complicating the profound and prolonged myelosuppression inevitably induced by high-dose chemotherapy remain a major factor of morbidity and mortality in patients undergoing autologous HCT $[3,4]$. The use of G-CSF after 

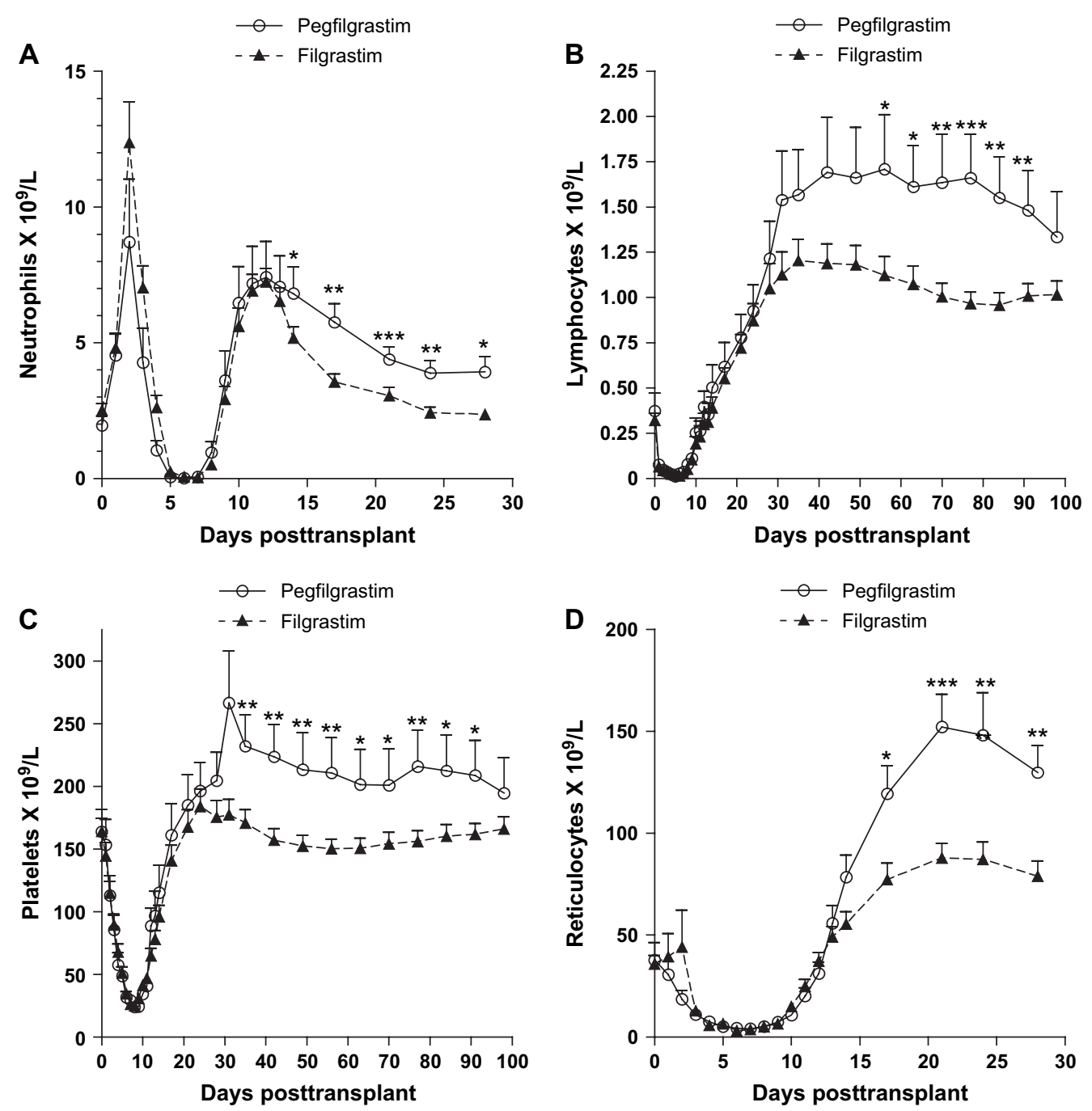

Figure 2. Neutrophil (A), lymphocyte (B), platelet (C), and reticulocyte (D) counts after transplantation in the Pegfilgrastim group compared with the Filgrastim group. ${ }^{*} p<0.05 ; * p<0.01 ; * * p<0.001$.

autologous bone marrow transplantation has been shown to shorten the duration of severe neutropenia and thereby to reduce the risk of infections [1,2,31]. Compared to transplantation of bone marrow, autologous infusion of PBSC is associated with a reduced period of neutropenia, fewer infectious complications, and shorter duration of hospitalization [32]. Several authors have reported that G-CSF can reduce the duration of early severe neutropenia by a few days to 1 week after high-dose chemotherapy and autologous transplantation of PBSC, which may then lead to a decreased incidence of infectious complications, reduced use of antibiotics, and shorter duration of hospitalization [512]. However, the duration of G-CSF action is limited by its removal from the body by two mechanisms. The first mechanism is thought to be mediated by G-CSF receptors (receptor-mediated clearance), predominantly on neutrophils [33-35]. The second process is likely the result of renal clearance $[34,35]$. A new form of Filgrastim, modified by the addition of PEG, has been produced. A single dose of Pegfilgrastim results in sustained drug concentration in serum $[17,20,22]$ thanks to the poly(ethylene glycol) modification of Filgrastim that causes decreased renal clearance of the protein [36].

Molineux et al. [15] demonstrated that a single injection of Pegfilgrastim produced significantly elevated neutrophil counts for 5 days in hematologically normal mice or for 9 to 10 days in normal human volunteers. In neutropenic mice, its effect was prolonged for at least 9 days and produced a significant reduction in the duration of chemotherapy-induced neutropenia. Johnston et al. [21] demonstrated that a single injection of Pegfilgrastim in NSCLC patients receiving chemotherapy was as safe and effective on ANC and $\mathrm{CD}_{3} 4^{+}$cell mobilization as daily Filgrastim. This efficacy and safety profile was confirmed by Holmes et al. $[16,17]$ in woman with breast cancer receiving chemotherapy. Vose et al. [18] illustrated similar effects of 
Table 3. Infectious complications after transplantation

\begin{tabular}{|c|c|c|c|}
\hline & Filgrastim & Pegfilgrastim & $p$ value \\
\hline $\begin{array}{l}\text { Duration of hospitalization } \\
\text { after transplant }\end{array}$ & $15.4 \pm 5.8$ & $14.5 \pm 3.3$ & 0.4991 \\
\hline Days with fever & $2.3 \pm 2.4$ & $2.7 \pm 2.3$ & 0.5140 \\
\hline Days on IV antibiotics & $8.4 \pm 5.9$ & $8.7 \pm 5.9$ & 0.8495 \\
\hline Days on IV amphotericin B & $1.7 \pm 5.1$ & $2.6 \pm 5.6$ & 0.5068 \\
\hline $\begin{array}{l}\text { Number of patients with } \\
\text { possible infection } \\
\text { (Fever of unknown origin) }\end{array}$ & $18(30 \%)$ & $8(40 \%)$ & 0.3857 \\
\hline $\begin{array}{l}\text { Number of patients } \\
\text { with bacteremia }\end{array}$ & $11(18 \%)$ & $7(35 \%)$ & 0.1221 \\
\hline $\begin{array}{l}\text { Number of patients } \\
\text { with other bacterial infection }\end{array}$ & $24(40 \%)$ & $7(35 \%)$ & 0.4082 \\
\hline $\begin{array}{l}\text { Number of patients } \\
\text { with fungal infection }\end{array}$ & $1(2 \%)$ & $1(5 \%)$ & 0.4082 \\
\hline $\begin{array}{l}\text { Number of patients } \\
\text { with CMV infection }\end{array}$ & $9(15 \%)$ & $9(45 \%)$ & 0.0053 \\
\hline $\begin{array}{l}\text { Number of patients } \\
\text { with CMV infections } \\
\text { among CMV + patients }\end{array}$ & $9(33 \%)$ & $9(56 \%)$ & 0.1409 \\
\hline $\begin{array}{l}\text { Number of patients } \\
\text { with CMV disease }\end{array}$ & $1(2 \%)$ & $0(0 \%)$ & 0.5612 \\
\hline $\begin{array}{l}\text { Number of patients } \\
\text { with CMV disease } \\
\text { among CMV + patients }\end{array}$ & $1(3 \%)$ & $0(0 \%)$ & 0.4360 \\
\hline $\begin{array}{l}\text { Number of patients with } \\
\text { Zoster infection }\end{array}$ & $4(6 \%)$ & $0(0 \%)$ & 0.2360 \\
\hline
\end{tabular}

Pegfilgrastim compared with daily Filgrastim in lymphoma patients undergoing salvage chemotherapy.

Farese et al. [22] examined the ability of a single injection of Pegfilgrastim to significantly improve neutrophil recovery following bone marrow transplantation in rhesus macaques and showed that the stimulation of granulopoiesis was equivalent to that observed with Filgrastim. A few studies have been conducted in patients undergoing PBSC transplantation. Soussain et al. [37] showed in 15 patients that a fixed 6-mg dose of Pegfilgrastim on day +3 was safe and effective. Musso et al. [25] observed that neutrophil engraftment, duration of hospitalization, and duration of intravenous antibiotics were similar in five patients receiving $6 \mathrm{mg}$ Pegfilgrastim on day +2 and five other patients treated with daily Filgrastim from day +5 . Musto et al. [26] demonstrated that $6 \mathrm{mg}$ Pegfilgrastim on day +3 and daily Filgrastim from day +5 (11 patients in both groups) had comparable safety and efficacy profiles. Neutrophil engraftment occurred 2 days earlier with Pegfilgrastim, corresponding to the delay in initiating the two treatments. Jagasia et al. [23] confirmed that a single 6-mg dose of Pegfilgrastim on day +1 appeared safe and accelerated neutrophil engraftment comparable to daily Filgrastim started on day +1 or +4 (38 patients in each group). However, these authors did not compare the clinical outcome of patients receiving Pegfilgrastim with that of patients receiving Filgrastim. Staber et al. [24] showed that a single 6-mg dose of Pegfilgrastim on day +5 reduced the duration of grade 4 neutropenia, the duration of febrile neutropenia, and the number of days of fever compared with daily Filgrastim started on day +7 (30 patients in each group).

However, in all these studies the two treatment modalities were started on differing days posttransplant (i.e., day +3 versus day +5 [26], day +2 versus day +5 [25], day +1 versus days +1 or +4 [23], and day +5 versus day +7 [24]). Our study compared 20 consecutive patients receiving Pegfilgrastim at a single dose of $6 \mathrm{mg}$ on day +1 after transplantation with a historical control group of 60 patients receiving Filgrastim at a daily dose of $5 \mu \mathrm{g} / \mathrm{kg}$ also starting on day +1 posttransplant. The kinetics of early hematopoietic recovery was quite similar in the two groups, including neutrophil, erythroid, and platelet reconstitution. There was no more use of additional G-CSF doses after initial hematopoietic recovery in the Pegfilgrastim group compared with the Filgrastim group. No difference was observed between the two groups for infectious events. Although we observed significantly more CMV infections in the group of patients receiving Pegfilgrastim, this was only due to a higher proportion of CMV-seropositive patients in this group. Our study had a similar design to the Jagasia study [23], although in that study, an unknown proportion of the patients started Filgrastim on day +4 . We achieved similar results for neutrophil recovery but other comparative data were not available in the Jagasia study [23].

Previous trials comparing Pegfilgrastim with Filgrastim outside of the transplant setting studied hematopoietic recovery after standard chemotherapy given in repeated cycles at intervals shorter than 4 weeks. Studies conducted in autologous transplant recipients only evaluated the impact of Pegfilgrastim on the primary hematopoietic recovery after autologous PBSC transplantation. Therefore, the evolution of blood cell counts could never be observed beyond day 30 postchemotherapy. In our study, a longer follow-up of 100 days posttransplant could be obtained. This may explain why we are the first to report a significant difference in the evolution of blood cell parameters in favor of the patients receiving Pegfilgrastim compared with those receiving Filgrastim. Indeed, we observed that neutrophil, lymphocyte, monocyte, reticulocyte, and platelet counts, although quite similar initially, were significantly higher in the group of patients receiving Pegfilgrastim during various periods of time after initial hematopoietic recovery. This took place despite a trend toward fewer CD34 ${ }^{+}$cells transplanted in the Pegfilgrastim group. One could speculate that this would suggest broader effects of Pegfilgrastim on progenitor cell recovery but this remains to be demonstrated. However, this discrepancy did not translate into differences in clinical outcome, probably because most infections occurred in the early period of neutropenia. This apparently superior effect on cell counts of Pegfilgrastim over Filgrastim should be confirmed in prospective randomized trials that should also address the question of cost-effectiveness of Pegfilgrastim in this setting. Musso et al. [25] also suggested that Pegfilgrastim 
administration could result in significant time savings for staff by reducing the number of drug administrations. With the convenience of a single-dose administration, Pegfilgrastim could become the future standard of care after autologous PBSC transplantation if its efficacy and cost can be proven to be at least equivalent to Filgrastim.

In our study, the cost of G-CSF was quite similar with Pegfilgrastim and Filgrastim. However, some studies have shown that postponing the initiation of G-CSF administration until day 5 or 6 posttransplant would not produce significant delays in neutrophil recovery $[12,38,39]$. Moreover, early discontinuation of G-CSF as soon as white blood cells reach a value of $1000 / \mu \mathrm{L}$ or neutrophils reach a value of $500 / \mu \mathrm{L}$ for 2 days after autologous hematopoietic stem cell transplantation is now being considered by some [40]. This would reduce the cost of Filgrastim administration and render Pegfilgrastim more expensive, unless a lower dose could do the job. However, in clinical practice, translating later initiation of Filgrastim treatment into lesser use of G-CSF is not straightforward. In the studies that compared daily Filgrastim with single-dose Pegfilgrastim, the number of Filgrastim doses ranged from seven when Filgrastim was started on day +7 [24] to 12 [26] or approximately 10 [25] when Filgrastim was started on day +5 , approximately 8 to 11 when Filgrastim was started on day +1 or +4 [23], and 10.7 in our study in which Filgrastim was started on day +1 . Therefore, initiating Filgrastim administration on day +5 does not automatically lead to fewer doses used compared with initiation on day +1 . Prospective randomized studies that compare Pegfilgrastim with Filgrastim, ideally started on the same day, are warranted.

\section{References}

1. Chopra R, McMillan AK, Linch DC, et al. The place of high-dose BEAM therapy and autologous bone marrow transplantation in poor-risk Hodgkin's disease. A single-center eight-year study of 155 patients. Blood. 1993;81:1137-1145.

2. Kirk JL Jr, Greenfield RA, Slease RB, Epstein RB. Analysis of early infectious complications after autologous bone marrow transplantation. Cancer. 1988;62:2445-2450.

3. Weaver CH, Schwartzberg LS, Hainsworth J, et al. Treatment-related mortality in 1000 consecutive patients receiving high-dose chemotherapy and peripheral blood progenitor cell transplantation in community cancer centers. Bone Marrow Transplant. 1997;19:671-678.

4. Toor AA, van Burik JA, Weisdorf DJ. Infections during mobilizing chemotherapy and following autologous stem cell transplantation. Bone Marrow Transplant. 2001;28:1129-1134.

5. Klumpp TR, Mangan KF, Goldberg SL, Pearlman ES, Macdonald JS. Granulocyte colony-stimulating factor accelerates neutrophil engraftment following peripheral-blood stem-cell transplantation: a prospective, randomized trial. J Clin Oncol. 1995;13:1323-1327.

6. Linch DC, Milligan DW, Winfield DA, et al. G-CSF after peripheral blood stem cell transplantation in lymphoma patients significantly accelerated neutrophil recovery and shortened time in hospital: results of a randomized BNLI trial. Br J Haematol. 1997;99:933-938.

7. Lee SM, Radford JA, Dobson L, et al. Recombinant human granulocyte colony-stimulating factor (filgrastim) following high-dose chemotherapy and peripheral blood progenitor cell rescue in high-grade
non-Hodgkin's lymphoma: clinical benefits at no extra cost. Br J Cancer. 1998;77:1294-1299.

8. Bence-Bruckler I, Bredeson $\mathrm{C}$, Atkins $\mathrm{H}$, et al. A randomized trial of granulocyte colony-stimulating factor (Neupogen) starting day 1 vs day 7 post-autologous stem cell transplantation. Bone Marrow Transplant. 1998;22:965-969.

9. Spitzer G, Adkins DR, Spencer V, et al. Randomized study of growth factors post-peripheral-blood stem-cell transplant: neutrophil recovery is improved with modest clinical benefit. J Clin Oncol. 1994;12:661670.

10. Schmitz N, Ljungman P, Cordonnier C, et al. Lenograstim after autologous peripheral blood progenitor cell transplantation: results of a double-blind, randomized trial. Bone Marrow Transplant. 2004; 34:955-962.

11. Dallorso S, Rondelli R, Messina C, et al. Clinical benefits of granulocyte colony-stimulating factor therapy after hematopoietic stem cell transplant in children: results of a prospective randomized trial. Haematologica. 2002;87:1274-1280.

12. Hornedo J, Sola C, Solano C, et al. The role of granulocyte colonystimulating factor (G-CSF) in the post-transplant period. Bone Marrow Transplant. 2002;29:737-743.

13. Zumberg MS, Leather HL, Nejame C, Meyer C, Wingard JR. GMCSF versus G-CSF: engraftment characteristics, resource utilization, and cost following autologous PBSC transplantation. Cytotherapy. 2002;4:531-538.

14. Delgado C, Francis GE, Fisher D. The uses and properties of PEGlinked proteins. Crit Rev Ther Drug Carrier Syst. 1992;9:249-304.

15. Molineux G, Kinstler O, Briddell B, et al. A new form of Filgrastim with sustained duration in vivo and enhanced ability to mobilize PBPC in both mice and humans. Exp Hematol. 1999;27:1724-1734.

16. Holmes FA, O'Shaughnessy JA, Vukelja S, et al. Blinded, randomized, multicenter study to evaluate single administration pegfilgrastim once per cycle versus daily filgrastim as an adjunct to chemotherapy in patients with high-risk stage II or stage III/IV breast cancer. J Clin Oncol. 2002;20:727-731.

17. Holmes FA, Jones SE, O'Shaughnessy J, et al. Comparable efficacy and safety profiles of once-per-cycle pegfilgrastim and daily injection filgrastim in chemotherapy-induced neutropenia: a multicenter dose-finding study in women with breast cancer. Ann Oncol. 2002; 13:903-909.

18. Vose JM, Crump M, Lazarus H, et al. Randomized, multicenter, openlabel study of pegfilgrastim compared with daily filgrastim after chemotherapy for lymphoma. J Clin Oncol. 2003;21:514-519.

19. Steidl U, Fenk R, Bruns I, et al. Successful transplantation of peripheral blood stem cells mobilized by chemotherapy and a single dose of pegylated G-CSF in patients with multiple myeloma. Bone Marrow Transplant. 2005;35:33-36.

20. George S, Yunus F, Case D, et al. Fixed-dose pegfilgrastim is safe and allows neutrophil recovery in patients with non-Hodgkin's lymphoma. Leuk Lymphoma. 2003;44:1691-1996.

21. Johnston E, Crawford J, Blackwell S, et al. Randomized, dose-escalation study of SD/01 compared with daily filgrastim in patients receiving chemotherapy. J Clin Oncol. 2000;18:2522-2528.

22. Farese AM, Yang BB, Roskos L, Stead RB, MacVittie TJ. Pegfilgrastim, a sustained-duration form of filgrastim, significantly improves neutrophil recovery after autologous marrow transplantation in rhesus macaques. Bone Marrow Transplant. 2003;32:399-404.

23. Jagasia MH, Greer JP, Morgan DS, et al. Pegfilgrastim after high-dose chemotherapy and autologous peripheral blood stem cell transplant: phase II study. Bone Marrow Transplant. 2005;35:1165-1169.

24. Staber PB, Holub R, Linkesch W, Schmidt H, Neumeister P. Fixeddose single administration of Pegfilgrastim vs daily Filgrastim in patients with haematological malignancies undergoing autologous peripheral blood stem cell transplantation. Bone Marrow Transplant. 2005;35:889-893. 
25. Musso M, Porretto F, Crescimanno A, Polizzi V, Scalone R, Mondello F. Filgrastim (G-csf) versus pegfilgrastim after autologous peripheral haematopoietic stem cell transplant in patients with haematological malignancies. Bone Marrow Transplant. 2005;35(Suppl. 2):S331.

26. Musto P, Scalzulli PR, Melillo L, et al. Peg-Filgrastim after autologous peripheral blood stem cell transplantation in hematological malignancies. Blood. 2004;104:384b.

27. Beguin Y, Baudoux E, Sautois B, et al. Hematopoietic recovery in cancer patients after transplantation of autologous peripheral blood CD34 + cells or unmanipulated peripheral blood stem and progenitor cells. Transfusion. 1998;38:199-208.

28. Sautois B, Fraipont V, Baudoux E, et al. Peripheral blood progenitor cell collections in cancer patients: analysis of factors affecting the yields. Haematologica. 1999;84:342-349.

29. Frere P, Hermanne JP, Debouge MH, de Mol P, Fillet G, Beguin Y. Bacteremia after hematopoietic stem cell transplantation: incidence and predictive value of surveillance cultures. Bone Marrow Transplant. 2004;33:745-749.

30. Cordonnier C, Engelhard D, Ljungman P, et al. Definitions of infectious diseases and complications after stem cell transplant. Web site of the EBMT. 2001. www.ebmt.org, accessed on 26-01-2006.

31. Welte K, Gabrilove J, Bronchud MH, Platzer E, Morstyn G. Filgrastim (r-metHuG-CSF): the first 10 years. Blood. 1996;88:1907-1929.

32. Schmitz N, Linch DC, Dreger P, et al. Randomised trial of filgrastimmobilised peripheral blood progenitor cell transplantation versus autologous bone-marrow transplantation in lymphoma patients. Lancet. 1996;347:353-357.
33. Layton JE, Hockman H, Sheridan WP, Morstyn G. Evidence for a novel in vivo control mechanism of granulopoiesis: mature cell-related control of a regulatory growth factor. Blood. 1989;74:1303-1307.

34. Kuwabara T, Kobayashi S, Sugiyama Y. Pharmacokinetics and pharmacodynamics of a recombinant human granulocyte colony-stimulating factor. Drug Metab Rev. 1996;28:625-658.

35. Petros WP. Pharmacokinetics and administration of colony-stimulating factors. Pharmacotherapy. 1992;12:32S-38S.

36. Yang BB, Lum PK, Hayashi MM, Roskos LK. Polyethylene glycol modification of filgrastim results in decreased renal clearance of the protein in rats. J Pharm Sci. 2004;93:1367-1373.

37. Soussain C, Marec L, Abarah W, Allard C, Mallek H, Itani C. Pegfilgastrim after high-dose chemotherapy and autologous peripheral blood stem cells transplantation. A single-centre experience in 15 patients. Blood. 2004;104:139b.

38. de Azevedo AM, Nucci M, Maiolino A, et al. A randomized, multicenter study of G-CSF starting on day +1 vs day +5 after autologous peripheral blood progenitor cell transplantation. Bone Marrow Transplant. 2002;29:745-751.

39. Faucher C, Le Corroller AG, Chabannon C, et al. Administration of GCSF can be delayed after transplantation of autologous G-CSF-primed blood stem cells: a randomized study. Bone Marrow Transplant. 1996; 17:533-536.

40. Valteau-Couanet D, Faucher C, Auperin A, et al. Cost effectiveness of day 5 G-CSF (Lenograstim) administration after PBSC transplantation: results of a SFGM-TC randomised trial. Bone Marrow Transplant. 2005;6:547-552. 